\title{
Parallels between Poor Internet Accessibility of LARC Information and West Virginia Teen Pregnancy
}

\author{
Andrya J. Durr \\ West Virginia University Health Sciences Center \\ Kelly M. Devlin \\ West Virginia University \\ Elizabeth A. Critch \\ West Virginia University \\ M. Paula Fitzgerald \\ West Virginia University John Chambers College of Business and Economics \\ Roberta I Renzelli-Cain ( $\nabla$ rir0001@hsc.wvu.edu ) \\ West Virginia University
}

Research article

Keywords: Long acting reversible contraception, Internet, pregnancy, teenagers, West Virginia

Posted Date: July 26th, 2019

DOl: https://doi.org/10.21203/rs.2.11968/v1

License: (c) (i) This work is licensed under a Creative Commons Attribution 4.0 International License. Read Full License 


\section{Abstract}

Background The purpose of this study was to investigate the availability of Long Acting Reversible Contraception (LARC) education on the websites of each of the West Virginia county health departments, and to determine if lack of readily accessible LARC information coincides with higher teenage pregnancy rates. Methods The West Virginia University National Center for Excellence in Women's Health investigated how many county health department websites had easily accessible references on their websites about birth control and specific information about LARC. Pearson correlation analysis was used to determine relationships between fixed broadband internet access and the teenage pregnancy and birth rates for females. Results These data demonstrate a significant correlation between increased percentages of the population without fixed broadband internet access, and the birth and pregnancy rates of females age 10 to 19, and show that only 12 of 55 counties provided accessible information on LARC, the most effective method of contraception. Conclusions In summary, we believe West Virginia should facilitate sustained internet access to its citizens. In order to help overcome communication and access barriers the state should provide consistent education on all health department websites regarding birth control options and how to use them.

\section{Background}

The United States boasts that $98 \%$ of its population has access to the internet.(1) Technology is a centerpiece of teenagers' lives-they freely use the internet and engage with smartphones, mobile apps, games, and streaming entertainment. Teenagers use the internet to watch movies, locate jobs, read books, and complete homework. Some teenagers even engage in cyber education programs, particularly student athletes, those who are homeschooled, and /or complete their high school education online. Public health officials, legislators, and members of the healthcare provider community assume that access to computers and high-speed internet connections is readily available to the public.

On any given day, American teenagers 13 to 18 average about nine hours of internet use, excluding time spent at school or doing homework.(2) Recently, the PEW Research Center and others report that internet use is almost constant among teenagers. $(3,4)$

Former president Barak Obama states "In this digital age when you can apply for a job, take a course, pay your bills, order pizza, even find a date [by using your connected phone], the internet is not a luxury, it is a necessity."(5) While more than $90 \%$ of households headed by a college graduate are connected, fewer than half of households with less than a high school education are plugged in.(5) This is relevant for a state like West Virginia due to its large population of people without high school diplomas or college degrees, and thus a significantly socioeconomically disadvantaged population.

Clearly, teenage use of internet and electronic devices is ubiquitous. In this paper, we look at the availability of consistent health information and its relationship to one of the most pressing issues facing the state of West Virginia; high teenage pregnancy rates. 
Only twenty-four states and the District of Columbia mandate sex education in public schools.(6) However, typical sex education is often focused on the science of reproductive biology mixed with the need for safe sex practices, yet the emphasis of the education efforts tends to be placed on abstinence. (7) Abstinence-only education has been proven ineffective in the reduction of teenage pregnancy rates.(8, 9) It also promotes shameful feelings in developing adolescents.(10) Emphasis on abstinence-only education increases the need for protection against sexually transmitted infections (STI) that can be transferred outside of sexual intercourse. $(8,9)$ This education dynamic results in a focus on STI prevention but protection against pregnancy is deemphasized.

Teenagers in the United States are more likely to give birth than in any other industrialized county in the world: $(11,12)$ they are more than 2.5 times as likely to give birth compared to teenagers from Canada; four times as likely as teenagers from Germany or Norway; and almost ten times as likely as teenagers from Switzerland.(11) Among developed countries, Russia has the next highest teen birth rate after the United States, but a teenage girl from the United States is still $25 \%$ more likely to give birth than her Russian counterpart.(11)

Despite being one of the twenty four states with sex education, West Virginia ranks $40^{\text {th }}$ in the nation for teenage pregnancy,(13) calling the quality of that education into question. Teenage pregnancies are associated with poor pregnancy outcomes such as: an increased need for cesarean section, high rates of infant mortality, preterm birth, and low birthweight infants.(14-16)

When looking at West Virginia's teenage pregnancy by county, it appears that there are major disparities within the state. The southernmost counties in West Virginia, Mingo and McDowell, have the highest teenage pregnancy and birth rates, almost double the national average. $(17,18)$ Aggregating county-level statistics (i.e., combining the southern counties with the more affluent counties with lower teenage pregnancy rates), negatively impacts these statistics and creates the misconception that the West Virginia teenage pregnancy rates are closer to the national average. Teenage pregnancy not only affects the adolescent, risking her physical and financial well-being, but also affects her male counterpart, their children, their families, and their community. $(19,20)$ Fourteen percent of West Virginia's sexually active adolescents did not use any method of birth control to prevent pregnancy during their last sexual intercourse. $(13,21,22)$

The American College of Obstetrics and Gynecology (ACOG), and the American Academy of Pediatrics (AAP) recommend Long Acting Reversible Contraceptive (LARC) methods as they have higher efficacy and patient satisfaction over their short acting counterparts. $(22,23)$ These methods differ from shortacting methods of birth control because they require minor office procedures for insertion, but they are not dependent on the patients' compliance.(22) In contrast, the efficacy of other widely used forms of short-acting birth control, such as birth control pills, is highly dependent on patient compliance. Despite the fact that ACOG and AAP recommend LARC for sexually active adolescents, only $5.8 \%$ of adolescents have ever used a LARC method. $(19,22,23)$ 
While LARC are an ideal contraceptive method for adolescents, there are many barriers when it comes to West Virginia's teenagers having access to these methods of birth control. $(24,25)$ Due to the high poverty rate and limited access to health care and transportation in the state, many women rely on health departments, Title X programs, Planned Parenthood, and Federally Qualified Health Centers as a source of information and medical care. $(25,26)$ West Virginia has a health department in every one of its fiftyfive counties,(27) but there may be disparities in young women's ability to gather information from West Virginia County Health Departments and the quality of on-line information provided by these public agencies. $(27,28)$

Although internet-based information gathering is a prominent method used by teenagers, limited fixed broadband internet access (the most reliable source of internet in West Virginia) may also be a major barrier to information about sexual and reproductive health.(29-31) Unfortunately, many rural areas in West Virginia remain at a disadvantage due to limited internet options and low-quality service. $(29,31)$ Thirty percent of West Virginia residents are without reliable internet access, three times higher than the national average of 10\%.(29) According to the United States Census Bureau, West Virginia has lower than the national average computer ownership and high-speed internet usage.(32) Efforts were made during the Obama administration to improve access to internet in the United States.(5) However, in West Virginia, the state initiative failed due to mismanagement of funds and there were accusations of impropriety. Reportedly, the state of West Virginia misspent funds delegated to improve internet access and the federal government demanded return of 4.7 million dollars.(30) Teenagers were deleteriously impacted because they rely heavily on internet access to learn and gather information. $(3,28)$

West Virginia is a state with increasingly difficult public and personal transportation amplified by only $31.7 \%$ of the population potentially owning a personal vehicle.(33) Health department websites are a primary resource for birth control and other health information. If information on birth control is not available on health department websites for the county of residence, the likelihood of being able to find and peruse that information, regardless of internet capabilities, is unlikely. These facts are pertinent to acknowledge when studying heavily rural states, as many residents cannot simply find care, or statespecific information elsewhere. For example, there is a single Planned Parenthood in the state that is centralized in Vienna, 167 miles from the heart of Mingo county. For many families living in poverty, 167 miles, a likely hotel stay, the cost of food, and a potential co-pay for treatment is daunting for a pack of pills.

\section{Methods}

The aim of this study was to investigate the availability of LARC education on the websites of each of the 55 West Virginia county health departments, and to determine if lack of readily accessible LARC information coincides with higher teenage pregnancy rates. We hypothesize that counties that do not provide information concerning LARC as a highly-effective contraceptive choice for teenagers will have higher rates of teenage pregnancy. Further, we examine correlations between the teenage pregnancy rate and availability of reliable internet access within their respective counties. Because of poor internet 
accessibility and inconsistent information across health department websites, we expect counties that experience difficulty obtaining reliable internet access and lack information from their county health departments regarding LARC to have higher teenage pregnancy rates.

In January of 2018, we, the West Virginia University National Center of Excellence in Women's Health, examined accessibility to online sources of birth control in the state of West Virginia, as well as accessibility to reliable internet capabilities. We first gathered county-specific data for reliable internet capabilities that was acquired from the Federal Communications Commission 2016 broadband progress report(29). We also included the county-level pregnancy and birth rates of females ages 10 to 19 between 2014 and 2017, acquired from the West Virginia Department of Health and Human Resources(21). Pearson correlation analysis was performed on a per-county basis between fixed broadband internet access and the birth and pregnancy rates among females ages 10 to 19.

Further, we investigated how many county health departments specifically discussed LARC on their websites. As previously discussed and supported by research by the Guttmacher Institute and the Pew Researcher Center, this is consistent with how adolescents and millennials gather information $(28,34)$. We constructed a map of the state detailing which counties' health departments provided easily accessible online information about LARC, and those that did not. Easily accessible was defined as information that was found on county health department websites via access to the family planning or birth control hotlink on the landing page. Once in the birth control or family planning link, only one click was permitted to access information about LARC.

\section{Results}

There is a significant correlation between increased percentages of the population without fixed broadband internet access and the birth rate to females age 10 to $19(r=0.270, p=0.046)$, and the teenage pregnancy rate to females ages 10 to19 $(r=0.239, p=0.079)$ (Table 1).

Twenty-two percent of counties provided readily accessible information on LARC, leaving $78 \%$ of health department websites without information about LARC (Figure 1). Figure 1 indicates whether or not information on LARC is provided by that county's health department website. A map of teenage pregnancy rates by county is also provided for reference (Figure 2)..

\section{Discussion}

Based on the results of this study, we determined that only 12 of 55 health department websites provided readily available information about LARC, but may have provided information about other types of contraception or redirected you to non-local, and in many cases federal, sources. Of the $78 \%$ of health department websites that did not provide readily available information on LARC, some provided information about other types of birth control or referenced other locations. For example, some health department websites contained no information about LARC or any type of birth control. Others provided 
information about oral contraceptive pills and other less effective methods, but failed to provide information about LARC. Hence, indicating that to learn about birth control a woman needs make an appointment with the clinic. Unfortunately, many links provided by other health departments or clinics were not located in the same county. The maps provided indicate both the availability of LARC information and the counties with the highest teenage pregnancy rates, revealing a pattern in which counties that have the highest teenage pregnancy rates appear to also be the counties in which the local health departments lack information about LARC.

This study reveals state-wide contraceptive and educational barriers for the state of West Virginia. Many barriers intrinsic to the state, including infrastructure and long distances from health care facilities, produce challenges for young women in their pursuit of information about birth control and access to health care. $(25,35,36)$ More than half of the state's population live in rural areas with transportation barriers and do not have access to health care providers familiar with the procedures required to place LARC. $(25,37)$ Limited access to face-to-face interaction regarding education on birth control options, combined with inadequate and inaccessible online information, leads to a large portion of adolescents with suboptimal sex education.(38)

These barriers prevent young women from accessing effective methods of contraception, and likely contribute to West Virginia's consistently high teenage pregnancy rates.(15, 35) Teenage pregnancy is only the beginning of problems young women face. Other challenges common place in the state include poverty, drug abuse, limited access to physician care, and reliable internet access. $(24,25,39)$ Teenagers often learn through the internet. Unfortunately, in West Virginia there is often a lack of access to reliable internet, or the county health department website provides incomplete or no information regarding the most reliable form of birth control for this age group, LARC. $(27,40)$ It is imperative that young people have consistent access to educational information regarding safe and effective birth control from credible sources, such as county health departments. Yet, much of West Virginia does not.

Further exploration is needed to determine how inconsistent internet capabilities impact the ability of teenagers to gather the information necessary to make informed reproductive decisions. Teenagers are unable to acquire information about LARC if the information is not available to them, but the fact remains that they are also unable to access it if they lack a reliable internet connection. Though internet accessibility is advertised to be available state-wide, in many pockets of the state, and especially rural areas, reliable connections are lacking. This is an under-considered challenge that West Virginia is facing in the wake of technology-based communication, and will likely impact the current adolescent generation to a greater extent than recent years.

The strengths of this study include a novel viewpoint of adolescent reproductive education, supported by inconsistencies in the information provided by the state and associations between dismal internet accessibility and teenage pregnancy and birth rates. Limitations of this study include the low socioeconomic status of West Virginia as a whole, that may influence both internet accessibility and the teenage pregnancy rate. Also, correlation analysis only provides relationships between teenage 
pregnancy and birth and internet access, and in no way implies causation, making conclusions drawn from this analysis inferences by the authors.

\section{Conclusions}

This shift in communication methods identifies the need for consistent messaging and information about all types of birth control, with emphasis on the efficacy and satisfaction associated with LARC, on all county health department websites. Allowing teenagers access to crucial information in ways they are comfortable and familiar with may overcome many communication barriers posed by the state, and contribute to a better informed and prepared generation that understands contraceptives and is empowered to reduce unintended pregnancy.

\section{List Of Abbreviations}

WV; West Virginia; LARC; long-acting reversible contraception, ACOG; American College of Obstetrics and Gynecology, AAP; American Academy of Pediatrics

\section{Declarations}

\section{Ethics approval and consent to participate}

Not applicable

\section{Consent for publication}

Not applicable

\section{Availability of data and material}

All data generated or analyzed during this study are included in this published article [and its supplementary information files].

\section{Competing interests}

The corresponding author is currently involved in an author writers' agreement with AbbVie Pharmaceuticals. The corresponding author is a speaker for Hologic-Cynosure. This association did not influence the methodology, analysis, or conclusions. 


\section{Funding}

This work was supported by the West Virginia University National Center of Excellence in Women's Health and also supported by the West Virginia University School of Medicine, Department of Obstetrics and Gynecology. This research did not receive any specific grant from funding agencies in the public, commercial, or not-for-profit sectors.

\section{Authors' Contributions}

$A D$ conceived of the study, participated in its design, performed data analysis, and was the primary writer for the manuscript; KD assisted in data organization and drafting of the manuscript; EC conceived of the study, participated in its design, assisted in drafting and finalization of manuscript; MPF assisted in data collection and analysis, and participated in drafting and finalization of manuscript; RRC conceived of the study, participated in its design, provided clinical oversight, and assisted in drafting and finalization of manuscript. All authors read and approved the final manuscript.

\section{Acknowledgements}

Not applicable

\section{References}

1.@WhiteHouse. 98 Percent of Americans Are Connected to High-Speed Wireless Internet: @WhiteHouse; 2015 [updated 2015-03-24. Available from: https://obamawhitehouse.archives.gov/blog/2015/03/23/98-americans-are-connected-high-speedwireless-internet.

2.Edwards MFaE. Teens Spend 'Astounding' Nine Hours a Day in Front of Screens: Researchers I WVEA 2019 [Available from: https://www.wvea.org/content/teens-spend-astounding-nine-hours-day-frontscreens-researchers.

3.Jiang MAaJ. Teens, Social Media \& Technology 2018: @pewinternet; 2018 [updated 2018-05-31. Available from: https://www.pewinternet.org/2018/05/31/teens-social-media-technology-2018/.

4.REACHOUT.com. Technology and teenagers - ReachOut Parents 2019 [Available from: https://parents.au.reachout.com/skills-to-build/wellbeing/technology-and-teenagers.

5.Eng DCaJ. Obama pledges to bring broadband internet to poor households 2015 [Available from: http://www.msnbc.com/msnbc/obama-pledges-bring-broadband-internet-poor-households. 
6.WDTV. West Virginia one of 8 states that require sex education classes to mention consent: @WDTV5News; 2019 [Available from: https://www.wdtv.com/content/news/West-Virginia-one-of-8states-that-require-sex-education-classes-to-mention-consent-494705391.html.

7.Younth Af. Sex Education Programs: Definitions \& Point-by-Point Comparison - Advocates for Youth 2019 [Available from: https://advocatesforyouth.org/resources/fact-sheets/sex-education-programsdefinitions-and-point-by-point-comparison/.

8.Stanger-Hall KF, Hall DW. Abstinence-Only Education and Teen Pregnancy Rates: Why We Need Comprehensive Sex Education in the U.S. PLoS One. 2011;6(10).

9.Santelli JS, Kantor LM, Grilo SA, Speizer IS, Lindberg LD, Heitel J, et al. Abstinence-Only-Until-Marriage: An Updated Review of U.S. Policies and Programs and Their Impact. The Journal of adolescent health: official publication of the Society for Adolescent Medicine. 2017;61(3):273-80.

10.Mintz L. Abstinence-Only Sex Ed: Harmful? Unethical?: Psychology Today; 2017 [Available from: https://www.psychologytoday.com/blog/stress-and-sex/201709/abstinence-only-sex-ed-harmfulunethical.

11.Kearney MS, Levine PB. Why is the teen birth rate in the United States so high and why does it matter? J Econ Perspect. 2012;26(2):141-66.

12.Institute G. Teen Pregnancy Rates Declined In Many Countries Between The Mid-1990s and 2011 Institute, Guttmacher2015 [updated 2015-01-23. Available from: https://www.guttmacher.org/newsrelease/2015/teen-pregnancy-rates-declined-many-countries-between-mid-1990s-and-2011.

13. Health OoA. West Virginia Adolescent Reproductive Health Facts | HHS.gov: @HHSgov; 2017 [updated 2017-05-30 00:00:00. Available from: https://www.hhs.gov/ash/oah/facts-and-stats/national-andstate-data-sheets/adolescent-reproductive-health/west-virginia/index.html.

14.Chaillet N, Dumont A. Evidence-based strategies for reducing cesarean section rates: a meta-analysis. Birth. 2007;34(1):53-64.

15.Goldthwaite LM, Duca L, Johnson RK, Ostendorf D, Sheeder J. Adverse Birth Outcomes in Colorado: Assessing the Impact of a Statewide Initiative to Prevent Unintended Pregnancy. Am J Public Health. 1052015. p. e60-6.

16.Lothian JA. Safe Prevention of the Primary Cesarean Delivery: ACOG and SMFM Change the Game. The Journal of Perinatal Education. 2014;23(3):115-8.

17.Control CfD. About Teen Pregnancy I CDC 2019 [updated 2019-03-01T06:27:33Z/. Available from: https://www.cdc.gov/teenpregnancy/about/index.htm. 
18.Teen birth (ages 15-19 per 1,000 females) I KIDS COUNT Data Center 2018 [Available from: https://datacenter.kidscount.org/data/map/5087-teen-birth-ages-15-19-per-1000-females/share/loc = 50 loct $=$ 5/5 any false 573 any 11519 Orange \#5/any/false/573/any/11519/Orange/.

19.Care CoAH. Adolescent Pregnancy, Contraception, and Sexual Activity - ACOG. The American College of Obstetricians and Gynecologists. 2019.

20.Irvine $\mathrm{H}$, Bradley $\mathrm{T}$, Cupples $\mathrm{M}$, Boohan $\mathrm{M}$. The implications of teenage pregnancy and motherhood for primary health care: unresolved issues. Br J Gen Pract. 1997;47(418):323-6.

21.West Virginia Department of Health and Human Resources 2018 [Available from: https://dhhr.wv.gov/Pages/default.aspx.

22.ACOG Committee Opinion No. 735: Adolescents and Long-Acting Reversible Contraception: Implants and Intrauterine Devices. Obstet Gynecol. 2018;131(5):e130-e9.

23.ACOG Strengthens LARC Recommendations - ACOG 2018 [Available from: https://www.acog.org/About-ACOG/News-Room/News-Releases/2015/ACOG-Strengthens-LARCRecommendations.

24.Goodman M, Onwumere O, Milam L, Peipert JF. Reducing health disparities by removing cost, access, and knowledge barriers. Am J Obstet Gynecol. 2017;216(4):382 e1- e5.

25.Reporter WHR-H. Barriers to rural health care go beyond transportation: @register_herald; 2018 [Available from: https://www.register-herald.com/news/barriers-to-rural-health-care-go-beyondtransportation/article_629c4e5e-87bf-5772-a9f6-069449f9f2f6.html.

26.Loda FA, Speizer IS, Martin KL, Skatrud JD, Bennett TA. Programs and services to prevent pregnancy, childbearing, and poor birth outcomes among adolescents in rural areas of the southeastern United States. The Journal of adolescent health: official publication of the Society for Adolescent Medicine. 1997;21(3):157-66.

27. Health WVCfL. Health Departments by County West Virginia Department of Health and Human Resources2018 [Available from: https://dhhr.wv.gov/localhealth/pages/map.aspx.

28. Institute G. American Adolescents' Sources of Sexual Health Information 2016 [updated 2016-04-12. Available from: https://www.guttmacher.org/fact-sheet/facts-american-teens-sources-information-aboutsex.

29.Commission FC. 2016 Broadband Progress Report 2016 [updated 2016-01-27. Available from: https://www.fcc.gov/reports-research/reports/broadband-progress-reports/2016-broadband-progressreport. 
30.writer EES. Feds order WV to pay back \$4.7M misspent on broadband project: @wvgazettemail; 2019 [Oct 7, 2017. Available from: https://www.wvgazettemail.com/business/feds-order-wv-to-pay-back-mmisspent-on-broadband/article_3e9e87d2-672e-59ef-b844-177ff467beb9.html.

31.Ettel G, 3rd, Nathanson I, Ettel D, Wilson C, Meola P. How do adolescents access health information? And do they ask their physicians? The Permanente journal. 2012;16(1):35-8.

32.Bureau USC. U.S. Census Bureau QuickFacts: West Virginia 2019 [Available from: //www.census.gov/quickfacts/wv.

33.Number of registered automobiles in West Virginia 2016 | Statistic 2019 [Available from: https://www.statista.com/statistics/196077/number-of-registered-automobiles-in-west-virginia/.

34.Piccorossi M. Teachers Say that for Students Today "Research = Googling" 2012 [Available from: https://www.pewresearch.org/fact-tank/2012/12/06/teachers-say-that-for-students-today-researchgoogling/.

35.Parks C, Peipert JF. Eliminating health disparities in unintended pregnancy with long-acting reversible contraception (LARC). Am J Obstet Gynecol. 2016;214(6):681-8.

36.Secura GM, Allsworth JE, Madden T, Mullersman JL, Peipert JF. The Contraceptive CHOICE Project: reducing barriers to long-acting reversible contraception. Am J Obstet Gynecol. 2010;203(2):115 e1-7.

37.Increasing Access to Contraceptive Implants and Intrauterine Devices to Reduce Unintended Pregnancy - ACOG 2018 [Available from: https://www.acog.org/Clinical-Guidance-andPublications/Committee-Opinions/Committee-on-Gynecologic-Practice/Increasing-Access-toContraceptive-Implants-and-Intrauterine-Devices-to-Reduce-Unintended-Pregnancy? IsMobileSet = false.

38.Coates C, Gordon CM, Simpson T. A Qualitative Study Exploring Contraceptive Practices and Barriers to Long-Acting Reversible Contraceptive Use in a Sample of Adolescents Living in the Southern United States. J Pediatr Adolesc Gynecol. 2018;31(6):605-9.

39.Collaborators USBoD, Mokdad AH, Ballestros K, Echko M, Glenn S, Olsen HE, et al. The State of US Health, 1990-2016: Burden of Diseases, Injuries, and Risk Factors Among US States. JAMA. 2018;319(14):1444-72.

40.Secura G. Long-acting reversible contraception: a practical solution to reduce unintended pregnancy. Minerva Ginecol. 2013;65(3):271-7.

\section{Table 1}

Table 1: Correlation between internet access and pregnancy/birth rates 

access
Pregnancy rate per 1,000 females ages 10 to 19
$0.239 *$

Births per 1,000 females ages 10 to 19

$0.270^{* *}$

Legend: Correlation between teenage pregnancy rates per 1,000 females ages 10 to 19 , and births per 1,000 females ages 10 to 19 to total \% of population without fixed broadband internet access.

*significant at $p<0.10$

**significant at $p<0.05$

\section{Figures}

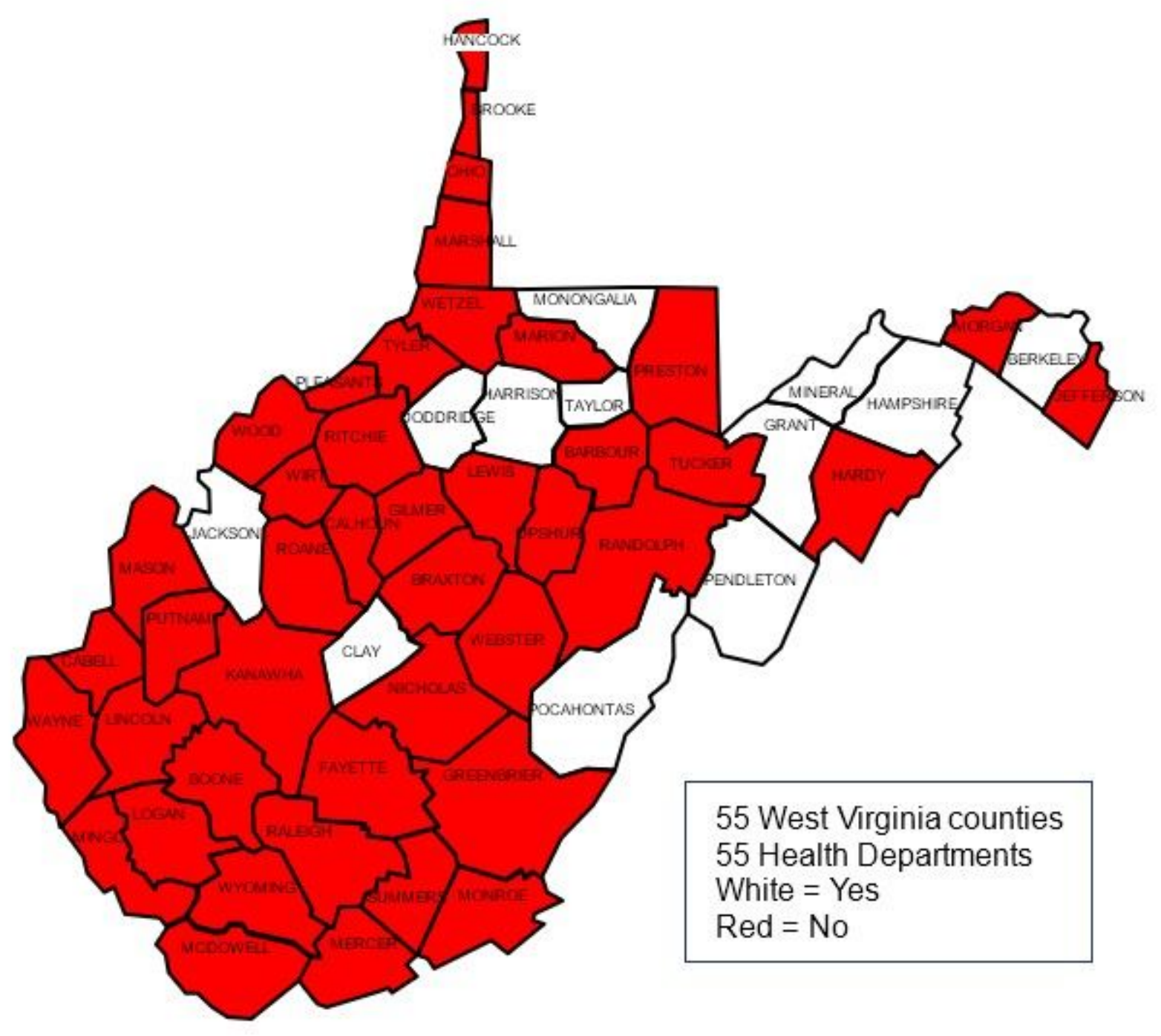

Figure 1 
Availably of readily available information regarding LARC from health department websites per county.

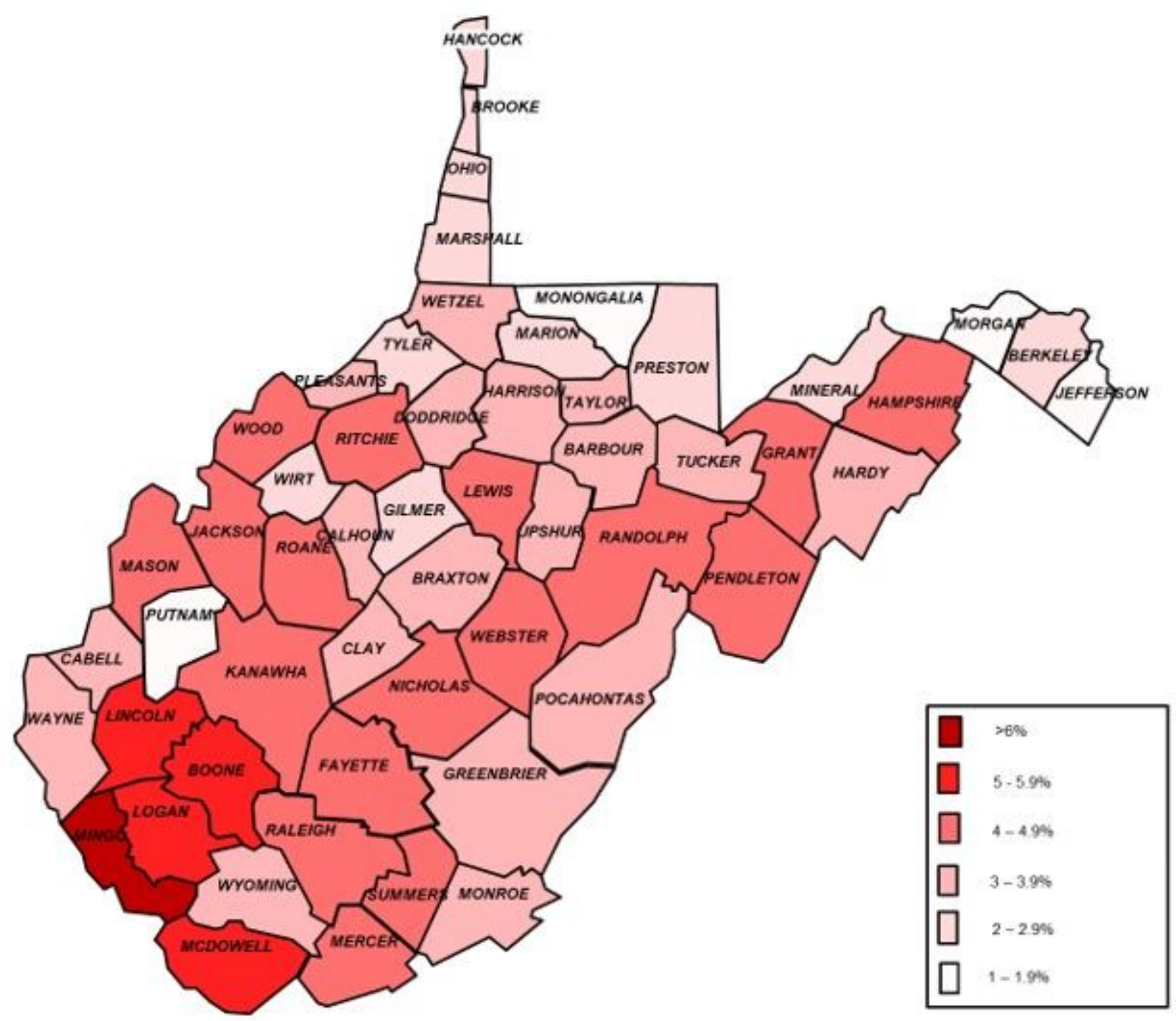

Figure 2

Teenage pregnancy rates by county for females ages 10 to 19 .

\section{Supplementary Files}

This is a list of supplementary files associated with this preprint. Click to download.

- supplement1.xIsx

- supplement2.xlsx 